\title{
Peritoneal Dialysis Catheters, Insertion Methods and Complications
}

\author{
Dr Klara Paudel \\ Charak Memorial Hospital, \\ Pokhara, Nepal \\ Email:klara.paudel@gmail.com
}

PJKD 2020;4(supplement 1):13-20

\begin{abstract}
The success of peritoneal dialysis (PD) and the PD program lies in a well-functioning catheter without infections. There are various types of catheters available and various insertion methods, although the difference in function and the outcome results are not markedly differentiated. In this review the types of commonly used peritoneal catheters and the variety of insertion methods will be introduced, along with special techniques and special catheters. This article will also list the complications that arise early, within 30 days of insertion. Comparing the main standard catheter variations and insertion methods, there is no difference in function and complications.
\end{abstract}

Keywords: Peritoneal dialysis, catheter, tenchkoff, hemodialysis, ESRD, swan neck catheter, exit site.

\section{Introduction}

According to estimates, the total worldwide dialysis population was 3.4 million in 2019 and will reach 3.7 million by $2020{ }^{1}$ Worldwide, $19 \%$ of end stage renal disease (ESRD) patients live with a transplanted kidney, $72 \%$ undergo hemodialysis (HD) and 9\% or 390000 patients are using peritoneal dialysis (PD). (see Table 1) However, the Asia Pacific region has a 23\% prevalence of PD. ${ }^{2}$

Table 1. Number of patients with End Stage Kidney Disease in 2019

\begin{tabular}{|l|c|c|}
\hline & 2019 & \\
\hline Patients with ESRD & $4,348,000$ & $100 \%$ \\
\hline Transplanted patients & 815,000 & $19 \%$ \\
\hline Dialysis patients & $3,533,000$ & $81 \%$ \\
\hline Hemodialysis (HD) & $3,143,000$ & $72 \%$ \\
\hline Peritoneal Dialysis (PD) & 390,000 & $9 \%$ \\
\hline
\end{tabular}

The most essential step to successful peritoneal dialysis is to provide peritoneal access with minimal complications. Catheter insertion techniques and catheter types play enormous role in achieving this.

In 1968, Tenckhoff and Schechter revolutionized the field of peritoneal dialysis by introducing a permanent catheter and a method of implantation that, for the first time, allowed relatively long periods of usage with a significant reduction in infections. The material chosen for the catheter was silicone.

Today, there are large numbers of catheter types available. Insertion techniques vary between nations and institutions, largely depending on skills and expertise. Which technique or catheter type is superior to the other is not always obvious. The aim of this review article is to provide information and summary on this topic.

\section{A: TYPES OF PERITONEAL DIALYSIS CATHETERS}

The most important purpose of the peritoneal dialysis catheter is to provide reliable and rapid dialysate flow rates without leaks or infections. The Tenckhoff catheter is still the most often used type, however there are many newer catheter designs. ${ }^{4}$ Variations of the peritoneal catheter include the number of cuffs (one versus two), the design of the subcutaneous pathway (extraperitoneal segment) and the intra-abdominal portion (intraperitoneal segment).

\section{Types of extraperitoneal segment:}

a. Swan neck: permanently bent. This type facilitates that the catheter will be downwards toward the pelvis and helps to prevent catheter tip migration. 


\section{PD: Catheter Insertion}

b. Straight : the subcutaneous tunnel segment of the catheter is straight. This type is easier to insert when using the percutanous blind method. Need to keep in mind the catheter shape memory, even though we try to bend it during insertion, the catheter will always want to straighten up again. (see Figure 1.)

Figure 1. Types of extraperitoneal segment of tunneled peritoneal dialysis catheters.

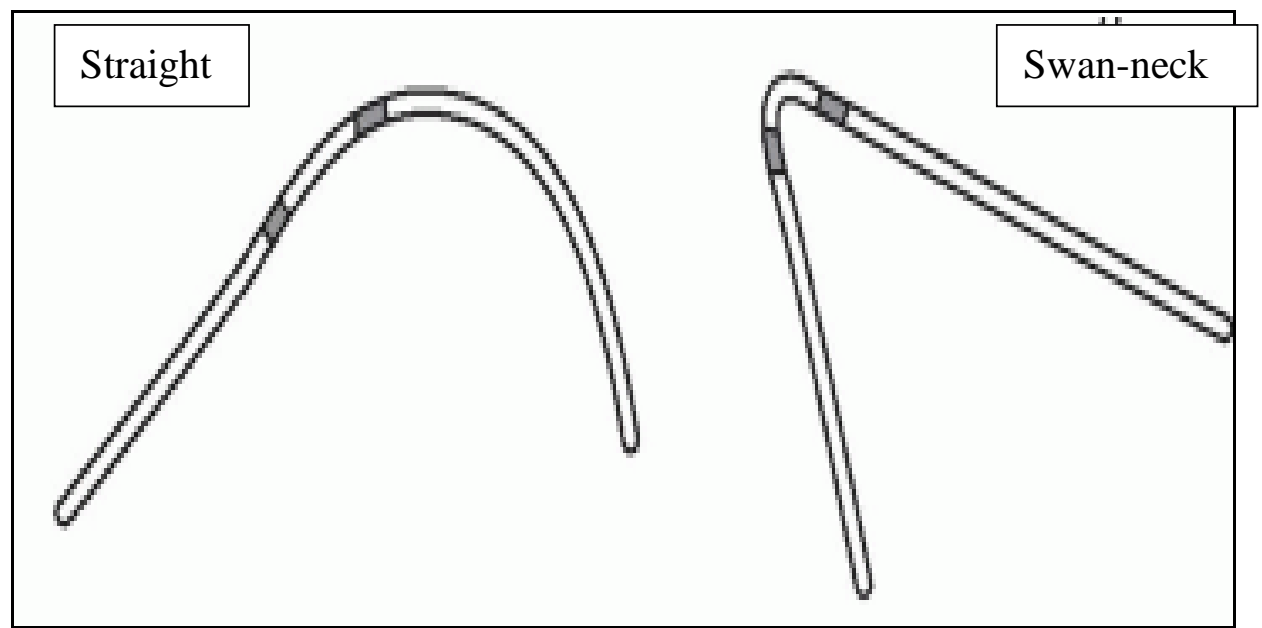

\section{Types of intraperitoneal segment:}

a. Straight: in this type the tip of the catheter is straight and has several small holes on the sides

b. Coiled: in this type the tip end portion of the catheter is rolled up, and forms a coil shape. The portion that has side holes is longer in this type. (see Figure 2.)

Figure 2: Types of intraperitoneal segment of tunneled peritoneal dialysis catheters.

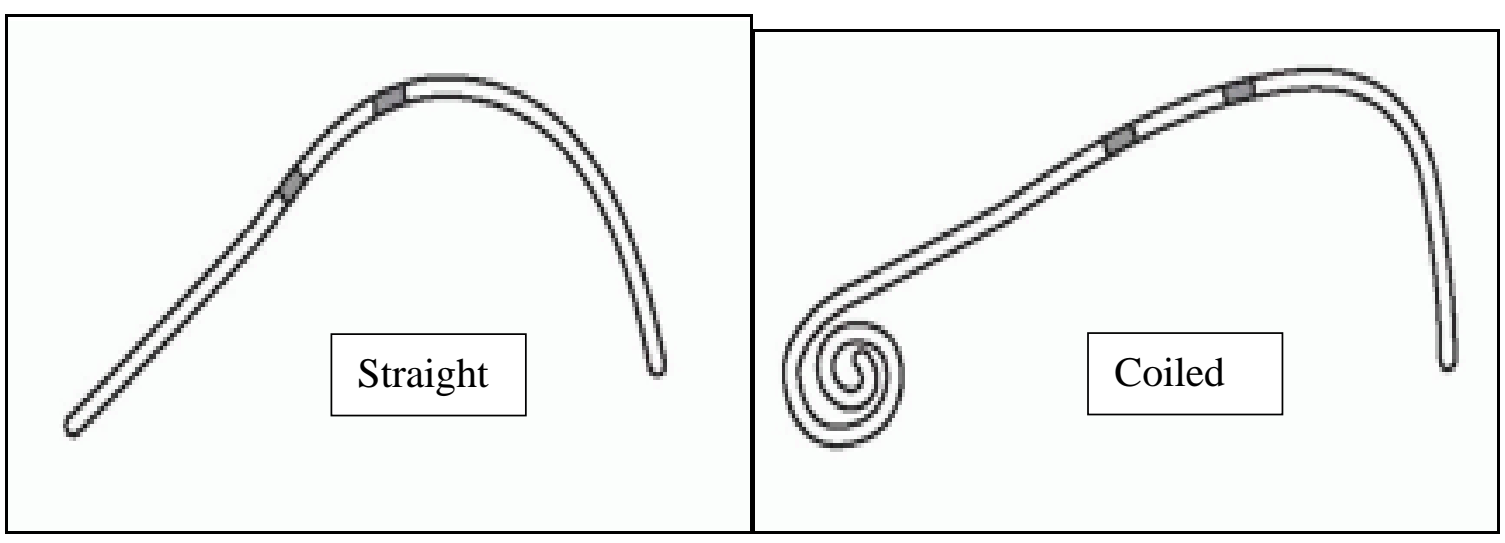

The above types of basic catheter designs comprise the mainstay of peritoneal access worldwide today. Alternative catheter designs were also developed, that are variations of these, designed to address or prevent specific issues with catheter complications.

\section{Alternative catheter designs:}

a. Oreopoulos-Zellerman (Toronto Western) variation: this design has two silicone disks at the end of the tubing aiming to keep bowel and omentum away from the side holes ${ }^{5}$ (see Figure 3.)

b. Di Paolo catheter: a tungsten weight is added to the tip of the catheter, thus through gravity it would be self-locating to the pelvis

c. Missouri catheter: a Dacron flange and silicon bead is added below and adjoining the deep cuff, in order to prevent pericatheter leaks.

d. Others: Pail-Handle (Cruz) catheter, Ash (Advantage) catheter, Moncrief-Popovich catheter, Presternal catheter and the Saudi 3-cuff catheter are other variations, (see details below in Sections 4 and in Table 2.) 


\section{PD: Catheter Insertion}

Contrary to expectations, most of these alternative catheter designs were not able to achieve their goal neither did they outperform the standard designs. Moreover, they were associated with increased cost and difficulty of insertion. ${ }^{6}$

\section{Difference in the outcome results of the various catheter types Outcome in Relation to Number of Cuffs:}

The single-cuff catheter is associated with a shorter time to the first peritonitis episode ${ }^{9-10}$ and has more exit-site complications, which indicate that double-cuff catheters should be used. However, a large retrospective cohort study suggested that the effect of the number of cuffs on peritonitis may be era related ${ }^{11}$ and is associated with exit site care and intranasal antibiotic protocols and the lower rate of Staphylococcus aureus carriers. ${ }^{12}$ The recommendation for best practices in 2019 clearly indicates the need for two-cuff catheters.

Figure 3: Various types of peritoneal dialysis catheters available world wide

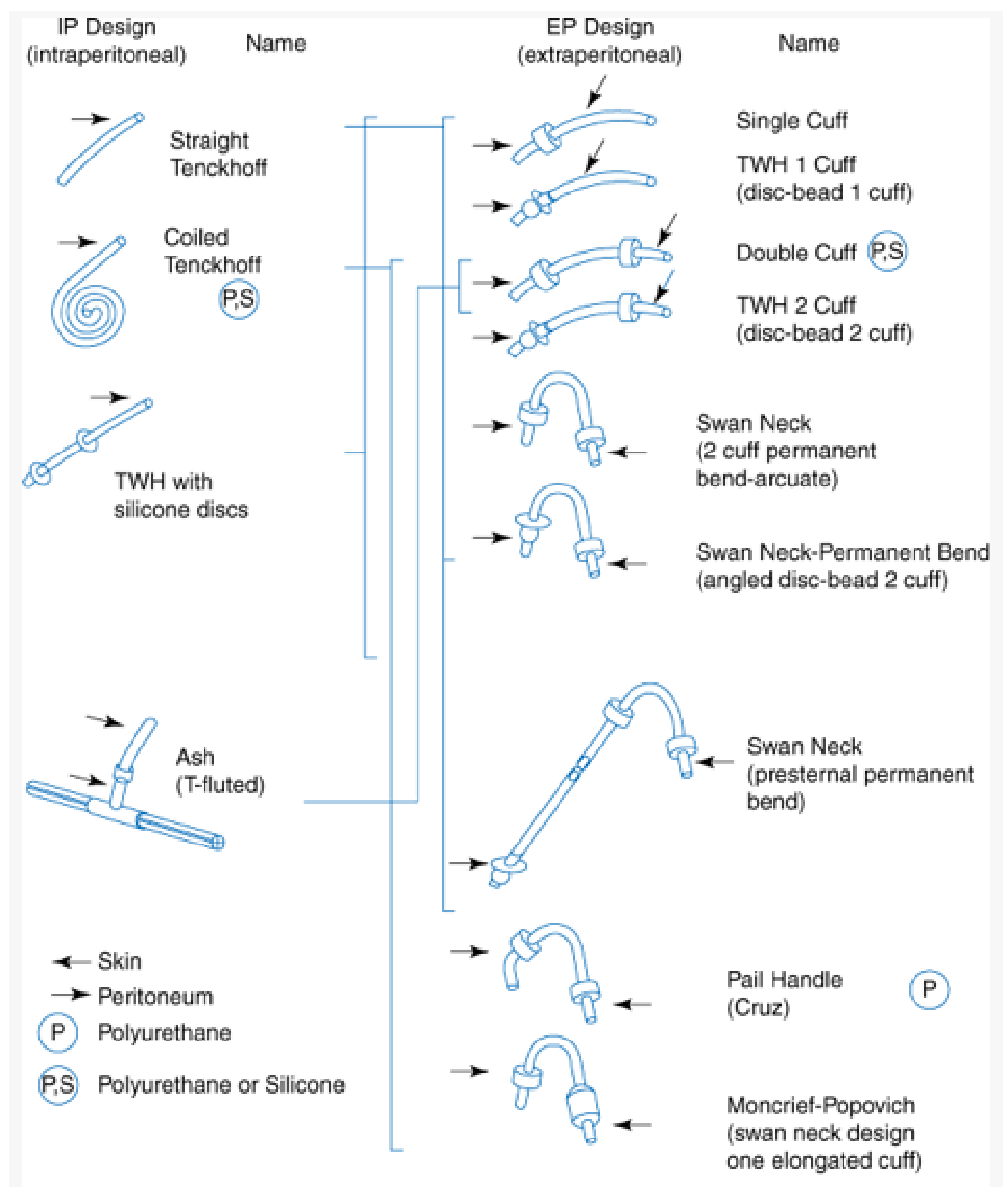

Source: Ref 7 Gokal R et.al. Peritoneal Dialysis International, 18(1), 11-33. 


\section{PD: Catheter Insertion}

Table 2: Characteristics of different peritoneal dialysis catheters.

\begin{tabular}{|c|c|c|c|c|c|}
\hline Catheter type & Material & Cuffs & $\begin{array}{l}\text { Shape of } \\
\text { intra-abdominal } \\
\text { segment }\end{array}$ & Inter-cuff shape & Characteristics \\
\hline Tenkhoff catheters & Silicone & $1-2$ & Straight/coiled & $\begin{array}{l}\text { Straight/ } \\
\text { Swan-Neck }\end{array}$ & \\
\hline $\begin{array}{l}\text { Toronto Western } \\
\text { Hospital (TWH) or } \\
\text { Oreopoulos- } \\
\text { Zellerman catheter }\end{array}$ & Silicone & 2 & Straight & Straight & $\begin{array}{l}\text { Dacron disc plus a } \\
\text { silicone rubber bead } \\
\text { (intraperitoneal } \\
\text { segment) }\end{array}$ \\
\hline $\begin{array}{l}\text { Swan-Neck Missouri } \\
\text { catheters }\end{array}$ & Silicone & $1-2$ & Straight/ coiled & $\begin{array}{l}\text { Swan-Neck (bend } \\
180^{\circ} \text { are angle) }\end{array}$ & $\begin{array}{l}\text { Bead and flange } \\
\text { (intraperitoneal } \\
\text { segment) }\end{array}$ \\
\hline $\begin{array}{l}\text { Pail-Handle (Cruz) } \\
\text { catheter }\end{array}$ & Polyurethane & 2 & Coiled & $\begin{array}{l}\text { Two bends }\left(90^{\circ} \text { arc }\right. \\
\text { angle) }\end{array}$ & \\
\hline $\begin{array}{l}\text { Presternal Swan- } \\
\text { Neck peritoneal } \\
\text { catheter }\end{array}$ & Silicone & $1-2$ & Straight/coiled & $\begin{array}{l}\text { Arcuate inter-cuff } \\
\text { shape }\end{array}$ & $\begin{array}{l}\text { Titanium connector } \\
\text { (between proximal } \\
\text { and distal-end) }\end{array}$ \\
\hline $\begin{array}{l}\text { Moncrief-Papovich } \\
\text { catheter }\end{array}$ & Silicone & 2 & Coiled & $\begin{array}{l}\text { Arcuate inter-cuff } \\
\text { shape }\end{array}$ & $\begin{array}{l}\text { Larger external cuff } \\
(2.5 \mathrm{~cm})\end{array}$ \\
\hline $\begin{array}{l}\text { Ash (Advantage) } \\
\text { catheter }\end{array}$ & Silicone & 2 & Straight & & T-shaped \\
\hline
\end{tabular}

"Because in several patients infusion pain occurred due to a "jet effect" and/or tip pressure on the peritoneum, the intraperitoneal segment of the catheters, was modified replacing a straight segment with a coiled one

Source: Ref 8: Haggerty, S Springer. 2017. Chapter 5. Overview of Catheter Choices and Implantation Techniques. ${ }^{8}$

\section{Outcome in Relation to Exit Site Direction:}

A downward-directed exit site was associated with lower peritonitis rates. ${ }^{9}$ In addition, the Network 9 study found that directing the subcutaneous portion of the catheter downward decreased the risk of peritonitis associated with exit-site and/or tunnel infection by $38 \%$, while an upward-directed catheter had a 50\% increased risk of catheter-related peritonitis, compared to horizontally-directed tunnels.

\section{Outcome in Relation to Extraperitoneal Segment Type:}

The peritonitis rate was significantly lower with permanent bent catheters according to a USRDS report. ${ }^{14}$ Other studies have also showed that the Swan-neck design was associated with less exit site infections."

\section{Recommendation of ISPD regarding PD catheter design}

The International Society of Peritoneal Dialysis (ISPD) recommends the following features of chronic peritoneal dialysis catheter in their best practice guideline published in $2019:^{6}$

1. We recommend catheters made of silicone rubber (1B)

2. We recommend that standard catheters be provided with double Dacron (polyester) cuffs (1C)

3. We recommend the use of catheters with either a straight or coiled tip with either a straight segment or preformed arc bend in the intercuff section $(1 \mathrm{C})$

4. We recommend the use of an extended catheter for remote exit-site location when standard catheters are unable to provide both optimal pelvic position and satisfactory exit-site location (1C)

\section{B. PD Catheter Insertion Techniques}

\section{Preimplantation Preparation}

The procedure, including the incidence and nature of complications, should be explained to the patient. Presurgical assessment is essential: search for herniation or weakness of the abdominal wall. Determination of the Exit Site: Prior to insertion, the exit site should be identified and marked on the skin (assess belt-line and the exit site should be either above or below the belt line, avoid skin folds or scars (use upright position) and the exit site should be lateral and visible by the patient). ${ }^{16}$ Bowel Preparation: Bowel preparation and the avoidance of constipation are of paramount importance. Similarly, emptying the bladder before the procedure is mandatory. Prophylactic Antibiotics Before Implantation: systemic antibiotics are highly effective in reducing early peritonitis postoperatively. Choice: should have a good gram positive cover such as cefazolin, vancomycin or other beta-lactam group antibiotics. ${ }^{17}$ Anticoagulation and antiplatelets should be hold before procedure, if it is possible. If these are used, the percutaneous blind method is not recommended.

\section{Percutaneous Blind Method}

This method uses the Seldinger technique. ${ }^{18}$ The first description of this method dates back to $1966 .{ }^{19}$ Major advantages are, that it can be done under local anaesthesia, can be done by the nephrologist, consumes shorter time, can be a day-care procedure for selected patients, and it is the least costly insertion method. Limitations of this method: not recommended in case of previous surgery in view of possible adhesions (exceptions: cholecystectomy, appendectomy, nephrotomy, gynecological surgeries and prior ultrasound can rule out adhesions in the proposed insertion site). 


\section{PD: Catheter Insertion}

Method: under local anaesthesia, a small incision is made below the umbilicus, usually in the midline or in lateral position (avoiding the area of the inferior epigastric artery). The subcutaneous tissue is dissected until the linea alba/rectus muscle is seen. Then an 18gauge needle is introduced into the peritoneum. To avoid injury to bowels, instead of the needle, a 16-gauge intravenous canule can be used, in which the needle is withdrawn immediately after introduction. Saline infusion is connected and free inflow can confirm the position in the peritoneum. A guide wire is inserted into the peritoneum and the needle is withdrawn. A dilator and peel-away sheath is advanced via the guidewire into the abdomen, directed towards the pelvis. The guidewire and dilator is withdrawn and the catheter is inserted via the peel-away sheath upto the first cuff. The peel-away sheath is teared away and removed, the catheter is in place and can be tested for inflow and outflow. Position of the catheter can be confirmed with fluoroscopy or ultrasound if needed. The exit site is created via a subcutanous tunnel $2-3 \mathrm{~cm}$ from the outer cuff. ${ }^{20}$

\section{Open Surgical Method}

This method uses a small incision in the peritoneum. The main advantage is the direct visualization of peritoneum that helps to avoid bowel injury and bleeding. Complex catheters can also be inserted via this method. Limitations: larger incision with higher chance for incisional hernia or leaks. Surgeon and Operation Theater are mandatory. Still no superiority compared to percutaneous insertion in the incidence of catheter migration or omental wrap resulting in malfunction.

Method: mini-laparotomy, under general or local anaesthesia. Skin incision in midline or para-medial location below the umbilicus line, then subcutaneous tissue dissected upto the rectus muscle. The muscle fibers of the rectus muscle are split and the peritoneum exposed with a small incision. The inside of the peritoneum can be explored by the operator's finger to look for adhesions. The catheter is inserted with a forcep or stylet, directing it towards the pelvis. The incision is closed with sutures and the subcutaneous tunnel with the exit site is created similarly to the percutaneous method. ${ }^{22}$

\section{Laparoscopic Method}

This method needs the laparoscopic technique with the involvement of experienced surgeon and equipment. Advantages: allows direct visualization of the abdomen and proper positioning of the catheter. Possible to perform associated procedures that increase success and catheter survival such as: omentecomy or omentopexy, fixation of the catheter into the pelvis with a suture, adhesiolysis. It requires small incision and less chance of incisional hernia or leaks. The catheter can be used immediately if needed.

Method: requires general anaesthesia. Veress needle or Hassan trocar is used to enter the peritoneal cavity. Pneumoperitoneum is formed and a diagnostic laparoscopy is done, if adhesions present, adhesiolysis can be performed. Then the catheter is inserted and the tip positioned in the pouch of Douglas. The tip can be fixed with a suture to avoid catheter migration. In the pediatric population an additional omentectomy or omentopexy is routinely done due to the high chance of omental wrap. Subcutanous tunnel and exit site is formed as in other methods. ${ }^{22}$

\section{Variations}

\subsection{Y-TEC method - Peritoneoscopic Technique}

This method requires a special equipment - Y-TEC (Medigroup, Inc. North Aurora, IL). ${ }^{24}$ It is done under local anaesthesia, can be performed by the nephrologist in a day-care setting. However, risk of bowel injury and bleeding is similar to the percutaneous method.

Method: Seldinger technique is used to insert the sheath into the peritoneum. Needlescope is inserted to visualize the pelvis after insufflation of the abdominal cavity. Catheter is inserted via the sheath. Exit site is created as in other methods. ${ }^{25}$

\subsection{Moncrief-Popovich method}

This method is used mainly for the purpose of early catheter insertion, to avoid emergency procedures and for those places, where there is a significant waiting time for elective catheter insertions. ${ }^{26}$ The end of the catheter is buried in the subcutaneous tissue and exit site is not formed at the time of catheter placement. After 4-8 weeks or even longer time, when the catheter is needed, it can be externalized with a simple incision in the skin. ${ }^{27}$

\subsection{Novel three-cuff Saudi Catheter with low pelvic insertion}

This catheter was developed in Saudi Arabia has been used during the last decade only. It has shown promising results with lower catheter migration and peritonitis rates. In a study on 150 incident PD patients who used the 3-cuff catheter, catheter migration was $0.0 \%$ and the rate of peritonitis was as low as 0.106 per patient-year equivalent to 1 episode of peritonitis per 112 patient-months. ${ }^{28}$ At the end of the study, catheter survival was $91.3 \%$. Other advantages of this novel catheter is the rapid fill and drainage time, which can lead to significant improvements in dialysis efficacy especially in automated peritoneal dialysis. ${ }^{29}$

Method: laparoscopic technique is used. The catheter insertion site is above the symphysis pubis and catheter tip is located at pouch of Douglas. The subcutaneous tunnel is longer with 3 cuffs and exit site will be at similar location as in other standard methods. ${ }^{2}$

\subsection{Extended presternal exit site}

This method can be used for patients with extreme obesity, large skin folds, feeding tubes or people who want to enjoy bath tubs. ${ }^{30}$ The exit site will be placed over the chest with a long subcutaneous tunnel. The tube is extended with titanium connector.

\section{Outcome measures of the various techniques}

There is no strong evidence that any catheter-related intervention, including the use of different catheter types or different insertion techniques, reduces the risks of PD peritonitis or other PD-related infections, technique failure or death (all causes). ${ }^{32-33}$ 


\section{PD: Catheter Insertion}

\section{A. COMPLICATIONS}

\section{Bleeding}

Bleed after insertion can be either from the exit site or intraperitoneally, presenting as red or pink effluent, however they are rarely causing significant problem. The incidence of major bleeding was $2 \%$ in a study of nearly 300 -catheter insertions. ${ }^{34}$

The bloody drain fluid should clear up within a few days, usually after a few exchanges. It is usually caused by trauma during insertion or antiplatelet use. Manual pressure or compression dressing, infiltration with adrenaline injection or additional suturing can stop persistent exit site bleeding. If the drainage contains blood, it is advised to use low dose heparin in the PD fluid to avoid blockage of the catheter.

\section{Infection}

Postoperative or early infection is uncommon, given the use of prophylactic antibiotics at the time of insertion. For the management of exit site or superficial wound infections antibiotics are usually sufficient. ${ }^{36}$

Early peritonitis with catheter placement may be a sign of a poor surgical technique or an unnoticed bowel injury. If the peritoneal fluid becomes cloudy, associated with pain, then the dialysate should be cultured and appropriate antibiotics must be administered. $^{37}$

\section{Bowel perforation}

Bowel perforation is rare, estimated to happen in about $1 \%$ of the insertions. ${ }^{38}$ The injury can happen during the entry into the abdominal cavity or when advancing the catheter with the stylet into the lower abdomen. Adhesions increase the chance for bowel injury. Significant perforation is suspected with the onset of pain, nausea or a rigid abdomen. Surgical exploration is mandatory with repair of the perforation and removal of the catheter, along with the use of intravenous antibiotics. ${ }^{38}$

\section{Bladder perforation}

Very rare complication that can happen during percutaneous catheter insertion in case of urinary retention or inadequate preparation. ${ }^{39}$ Bladder should be emptied just before the procedure to keep the bladder empty. While a urinary catheter is routinely used in many institutions to avoid bladder injury during blind insertion, it is not mandatory. In elderly patients with high risk for prostate hypertrophy, it may be necessary. If equipment or expertise permits, it is also possible to do a quick ultrasound scan before insertion to make sure the bladder is not full. Fluoroscopy guidance can help to recognize this complication at the time of insertion. In case the catheter is mistakenly inserted into the bladder, the main sign will be that the patient will have urgency to urinate immediately after inflow of the dialysate. Catheter should be removed and the bladder wall repaired in these cases.

\section{Flow problems - inflow failure, outflow failure}

Inflow or outflow failure may be due to multiple causes, including: clots or fibrin in the catheter, kink in the subcutaneous tunnel, placement of the catheter in the extraperitoneal space or into the omentum, development of omental wrap or adhesions in the abdomen. ${ }^{41}$ Initially a heparin lock can be administered $(1 \mathrm{ml}$ of heparin diluted in $19 \mathrm{ml}$ of saline) and inserted into the catheter, kept for 30 minutes, then PD flush tested. If flow is still not sufficient, an abdominal X-ray can help to see catheter and tip position. Ultrasound can detect omental wrap or catheter misplacement. In about 50\% of cases, simple measures will restore catheter function. However, some cases will need surgical repositioning with omentectomy or omentopexy. ${ }^{21}$

\section{Catheter tip migration}

Malpositioning of the catheter into the upper abdomen usually causes pain and sometimes outflow failure. A plain abdominal radiological examination, eventually with a fluoroscopic contrast study, can reveal this problem. Conservative measures with laxatives to activate bowel movements, which will carry the catheter into the right position, are usually disappointing. Catheter repositioning with a stiff guide wire or forceps can be successful and causes little morbidity. ${ }^{42}$ In this technique, a device such as a malleable rod, guide wire, cannula or tip-deflecting wire, is inserted into the catheter and is used to redirect or reposition the catheter tip in a more favourable position for PD. Laparoscopic repositioning with catheter fixation into the lower abdomen may be the ultimate therapy to solve this problem. Prevention of catheter malposition remains the major goal and can be adjusted by a laparoscopic insertion technique and correct measurement of catheter length.

Insertion techniques to prevent catheter migration have been tried with promising results, however it requires special skills, such as open method with one internal stich. ${ }^{43}$

The Saudi catheter is designed in such way that there is $0 \%$ catheter migration in their cohort. ${ }^{29}$

\section{Leaks}

Leakage of dialysate can be deducted with fluid drainage from the exit site or with the appearance of a bulge underneath the entrance site. ${ }^{44}$ Causes of leaks may be due to hernia at the entrance site as a result of very large incision, positioning of the proximal cuff on the rectus muscle, and trauma. Catheter rest without dialysate instillation for some weeks is most likely to solve this problem. Temporary HD treatment is usually required. ${ }^{45}$

\section{Hernia}

Hernia could be a preexisting undetected hernia or it can develop after initiation of PD. ${ }^{46}$ Common sites for hernia to develop can be incisional hernia if the incision site is too long. Preexisting abdominal wall defects will show as swelling and pain after PD fluid instillation and reduced drain volumes. For preexisting hernias, the best management is to repair the hernia simultranously with PD catheter insertion. For hernia that developes after PD initiated, the management involves hernia repair and temporary stop in PD for 2 weeks at minimum. ${ }^{47}$ 


\section{PD: Catheter Insertion}

\section{CONCLUSION}

There are countless numbers of variations to peritoneal dialysis catheters, however the standard Tenckhoff catheters are the ones used in the majority of centers. There is no significant difference proven between the four main types of standard catheters (straight/swan neck and straight/coiled). There is also no difference in the long-term outcomes between the various insertion methods. Some catheter types and some insertion method modifications may prevent certain complications, however they need further studies.

\section{References}

1. FMC report 2019 - Fresenius Medical Care: Fresenius Medical Care Annual Report 2019. Bad Homburg, Fresenius Medical Care, 2019.

2. Jain AK, Blake P, Cordy P, Garg AX: Global trends in rates of peritoneal dialysis. J Am Soc Nephrol 2012;23:533-544.

3. Tenckhoff H, Schechter H. A bacteriologically safe peritoneal access device. Trans Am Soc Artif Intern Organs. 1968;14:181-187.

4. Lupo A, Tarchini R, Cancarini G, Catizone L, Cocchi R, De Vecchi A, et al. Long-term outcome in CAPD: A 10 year survey by the Italian Cooperative Peritoneal Dialysis Study Group. Am J Kidney Dis 1994; 24:826 - - 37.

5. Khanna, R., Krediet, R. Nolph and Gokal`s Textbook of Peritoneal Dialysis. Springer. 2009. Chapter 1. History of Peritoneal Dialysis.

6. Crabtree JH, Shrestha BM, Chow KM, et al. Creating and Maintaining Optimal Peritoneal Dialysis Access in the Adult Patient: 2019 Update. Perit Dial Int 2019; 39:414.

7. Gokal, R., Alexander, S., et al. (1998). Peritoneal catheters and exit-site practices toward optimum peritoneal access: 1998 update. Peritoneal Dialysis International, 18(1), 11-33.

8. Haggerty, S.: Surgical Aspects of Peritoneal Dialysis. Springer. 2017. Chapter 5. Overview of Catheter Choices and Implantation Techniques

9. Warady BA, Sullivan EK, Alexander SR. Lessons from the peritoneal dialysis patient database: a report of the North American Pediatric Renal Transplant Cooperative Study. Kidney Int 1996; 49(Suppl 53):S68 - - 71.

10. Honda M, Litaka K, Kawaguchi H, Hoshi S, Akashi S, Kohsaa T, et al. The Japanese National Registry Data in Pediatric CAPD Patients: A report of the study group of pediatric conference. Perit Dial Int 1996;16:269 - 75.

11. Nessim SJ, Bargman JM, Jassal SV Relationship between double-cuff versus single-cuff peritoneal dialysis catheters and risk of peritonitis. Nephrol Dial Transplant 2010; 25:2310 - 4.

12. Vychytil A, Lorenz M, Schneider B et al. New strategies to prevent Staphylococcus aureus infections in peritoneal dialysis patients. J Am Soc Nephrol 1998; 9:669 - 76.

13. Golper TA, Brier ME, Bunke M. Risk factors for peritonitis in long-term peritoneal dialysis: The Network 9 Peritonitis and Catheter Survival Studies. Am J Kidney Dis 1996; 38:428 - - 36.

14. US Renal Data System 1992. Annual data report VI. Catheter related factors and peritonitis risk in CAPD patients. Am J Kidney Dis 1992; 20(Suppl 2):48 - - 54.

15. Lo W.K. Lui S.L. Li F.K. et al. A prospective randomized study on three different peritoneal dialysis catheters. Perit Dial Int. 2003; 23: S127-S131

16. Amici G, Bernacconi T, Bonforte G et al. The peritoneal dialysis catheter. Journal of Nephrology 2013; 26( Suppl 21): S4-S75

17. Szeto CC, Li PK, Johnson DW, et al. ISPD catheter-related infections recommendations: 2017 update. Perit Dial Int. 2017;37:141 - 54.

18. Seldinger SI. Catheter replacement of the needle in percutaneous arteriography, a new technique. Acta Radiol. 1953;39(5):368-76.

19. Jeresaty RM, Amato JA, Huszar RJ. Application of Seldinger's Percutaneous Method to Peritoneal Dialysis - Experimental Study. JAMA. 1966;197(1):59-60

20. Zappacosta AR, Perras ST, Closkey GM. Seldinger technique for Tenckhoff catheter placement. ASAIO Trans. 1991;37(1):13-5.

21. Peppelenbosch A, Van Kuijk WHM, Bouvy ND, et al. Peritoneal dialysis catheter placement technique and complications. NDT Plus. 2008;1(1):23-28

22. Crabtree JH, Chow KM. Peritoneal Dialysis Catheter Insertion. Semin Nephrol 2017; 37:17.

23. Amerling R, Cruz C. A new laparoscopic method for implantation of peritoneal catheters. ASAIO J. 1993;39:M787 - M789.

24. Yorg Al Azzi, Etti Zeldis, Jaime Uribarri et al. Outcomes of dialysis catheters placed by the Y-TEC peritoneoscopic technique: a singlecenter surgical experience. Clin Kidney J. 2016 ; 9(1): 158 - 161.

25. Gadallah MF, Pervez A, El-Shahawy M, Sorrells D, et al. Peritoneoscopic versus surgical placement of Tenckhoff catheters: a prospective study on outcome. J Am S Nephrol 1996; 7(9):A0904.

26. Moncrief JW, Popovich RP, Simmons EE, et al. The Moncrief-Popovich catheter: a new peritoneal access technique for patients on peritoneal dialysis. ASAIO J 1993; 39(1):62-5.

27. Moncrief JW, Popovich RP, Seare W, et al. Peritoneal dialysis access technology: the Austin Diagnostic Clinic experience. Perit Dial Int 1996; 16 Suppl 1:S327.

28. Hwiesh AKAI, Rahman ISA, Audah NAI, et al. A Novel three cuff peritoneal dialysis catheter with low entry technique: three years single center experience. Urol Nephrol Open Access J. 2017;4(5):150-156. DOI: 10.15406/unoaj.2017.04.00143

29. Al-Hwiesh AK. A modified peritoneal dialysis catheter with a new technique: Farewell to catheter migration. Saudi J Kidney Dis Transpl 2016;27:281-9

30. Twardowski ZJ, Nichols WK, Nolph KD, Khanna R. Swan neck presternal (bath tub) catheter for peritoneal dialysis. Adv Perit Dial 1992;8:316 - 24.

31. Twardowski, ZJ. Presternal peritoneal catheter. Adv Ren Replace Ther. 2002 Apr;9(2):125-32.

32. Htay H, Johnson DW, Craig JC, et al. Catheter type, placement and insertion techniques for preventing catheter-related infections in chronic peritoneal dialysis patients. Cochrane Database Syst Rev 2019; 5:CD004680.

33. Dogra P M, Hooda A K, Shanmugraj G, Pramanik S K. Continuous ambulatory peritoneal dialysis catheter insertion technique: A comparative study of percutaneous versus surgical insertion. Indian J Nephrol 2018:28:291-7

34. Mital S1, Fried LF, Piraino B. Bleeding complications associated with peritoneal dialysis catheter insertion. Perit Dial Int. $2004 ; 24(5): 478-80$.

35. Li JR, Chen CH, Chiu KY, et al. Management of pericannular bleeding after peritoneal dialysis catheter placement. Perit Dial Int. 2012;32(3):361 - 362.

36. Liu X, Zuo X, Sun X, Hu Z. Effects of prophylactic antibiotics before peritoneal dialysis catheter implantation on the clinical outcomes of peritoneal dialysis patients. Ren Fail. 2019;41(1):16 - 23.

37. Bender, F.H. et al. Prevention of infectious complications in peritoneal dialysis: best demonstrated practices. Kidney International, November 2006, Volume 70, S44 - S54

38. Abreo K, Sequeira A. Bowel Perforation During Peritoneal Dialysis Catheter Placement. Am J Kidney Dis. 2016;68(2):312-315.

39. Guilcan E, Seval Yildiz Sahin SY, Mehmet Korkmaz M, Kabak O. A Rare Complication During Percutaneous Peritoneal Dialysis Catheter Insertion: Intravesical Placement. Advances in Peritoneal Dialysis 2018;34:61-63

40. Riar S, Abdulhadi M, Prasad B. Accidental Insertion of a Peritoneal Dialysis Catheter in the Urinary Bladder. Case Rep Nephrol Dial. 2018; 8(1): $76-81$. 


\section{PD: Catheter Insertion}

41. Brendan B. McCormick and Joanne M. Bargman Noninfectious Complications of Peritoneal Dialysis: Implications for Patient and Technique Survival JASN December 2007,18 (12) 3023-3025;

42. Ma T.K.-W. Chow K.M. Kwan B.C.-H. et al.Peritoneal Dialysis Catheter Revision and Replacement by Nephrologist for Peritoneal Dialysis Catheter Malfunction. Nephron 2018;138:214 - 219

43. Chen, Wen-Ming \& Li, Jian-ri. A Simple Method to Prevent Peritoneal Dialysis Catheter Tip Migration. Peritoneal Dialysis International 2007 27. 554-6.

44. Leblanc M, Ouimet D, Pichette V. Dialysate leaks in peritoneal dialysis. Semin Dial 2001; 14:50.

45. Holley JL, Praino BM. Complications of peritoneal dialysis: Diagnosis and management. Semin Dial 1990; 3:245.

46. Rocco, MV, Stone, WJ. Abdominal hernias in chronic peritoneal dialysis patients: A review. Perit Dial Bull 1985; 5:171.

47. Suh H, Wadhwa NK, Cabralda T, et al. Abdominal wall hernias in ESRD patients receiving peritoneal dialysis. Adv Perit Dial 1994; 10:85. 